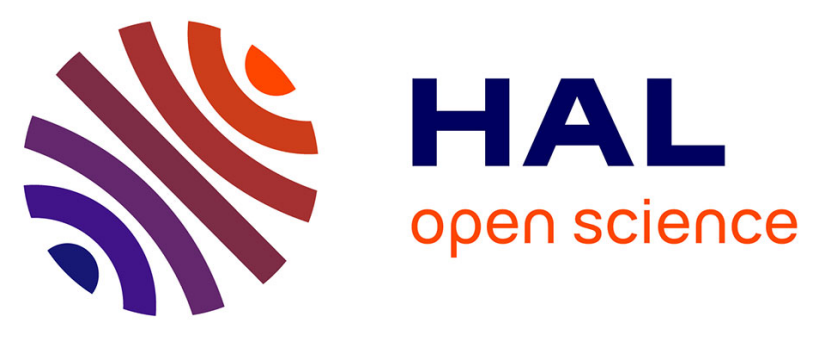

\title{
Photodegradation of fluorene in aqueous solution: Identification and biological activity testing of degradation products
}

Said Kinani, Yasmine Souissi, Aziz Kinani, Svetlana Vujovic, Selim Ait-Aissa, Stéphane Bouchonnet

\section{To cite this version:}

Said Kinani, Yasmine Souissi, Aziz Kinani, Svetlana Vujovic, Selim Ait-Aissa, et al.. Photodegradation of fluorene in aqueous solution: Identification and biological activity testing of degradation products. Journal of Chromatography A, 2016, 1442, pp.118-128. 10.1016/j.chroma.2016.03.012 . ineris-01862937

\section{HAL Id: ineris-01862937 \\ https://hal-ineris.archives-ouvertes.fr/ineris-01862937}

Submitted on 28 Aug 2018

HAL is a multi-disciplinary open access archive for the deposit and dissemination of scientific research documents, whether they are published or not. The documents may come from teaching and research institutions in France or abroad, or from public or private research centers.
L'archive ouverte pluridisciplinaire HAL, est destinée au dépôt et à la diffusion de documents scientifiques de niveau recherche, publiés ou non, émanant des établissements d'enseignement et de recherche français ou étrangers, des laboratoires publics ou privés. 


\section{Photodegradation of fluorene in aqueous solution: identification and biological activity testing of degradation products}

Said Kinani ${ }^{\mathrm{a}}$, Yasmine Souissia ${ }^{\mathrm{a}}$, Aziz Kinani ${ }^{\mathrm{a}}$, Zvetlana Vujovića ${ }^{\mathrm{a}}$, Sélim Aït-Aïssa ${ }^{\mathrm{b}}$ and Stéphane Bouchonnet ${ }^{\mathrm{a}, *}$

${ }^{a}$ Laboratoire de Chimie Moléculaire - École Polytechnique - 91128 Palaiseau, France

${ }^{\mathrm{b}}$ Unité Écotoxicologie in vitro et in vivo, Institut National de l'Environnement Industriel et des Risques (INERIS), BP 2, F-60550 Verneuil en Halatte, France

* Corresponding author, e-mail: stephane.bouchonnet@polytechnique.edu

\section{HIGHLIGHTS}

Degradation of fluorene under UV-Vis irradiation in water was investigated.

Twenty six photoproducts were characterized using GC-MS coupling.

Competing photodegradation pathways of fluorene under UV-Vis irradiation have been suggested.

Some photoproducts of fluorene are biologically much more active than the parent compound.

\section{ABSTRACT}

Degradation of fluorene under UV-Vis irradiation in water was investigated and structural elucidation of the main photoproducts was achieved using gas chromatography coupled with mass spectrometry. Twenty-six photoproducts were structurally identified, mainly on the basis of electron ionization mass spectra interpretation. The main generated transformation products are hydroxy derivatives. Some secondary photoproducts including fluorenone, hydroxy fluorenone, 2-biphenyl carboxylic acid, biphenylene, methanol fluorene congeners and hydroxy fluorene dimers were also observed. A photodegradation pathway was suggested on the basis of the chemical structures of photoproducts. Fluorene as well as its main photoproducts for 
26 which chemical standards were commercially available were tested for their ability to elicit 27 cytotoxic, estrogenic and dioxin-like activity by using in vitro cell-based bioassays. None of 28 the tested compounds was cytotoxic at concentrations up to $100 \mu \mathrm{M}$. However, 229 hydroxyfluorene and 3-hydroxyfluorene exerted significant estrogenic and dioxin-like activity 30 on a concentration range of 3-30 $\mu \mathrm{M}$, while fluorene and 9-hydroxyfluorene were weakly or 31 not active, respectively, in our assays. This supports the view that photodegradation processes 32 can generate by-products of higher toxicological concern than the parent compound and 33 strengthens the need to further identify transformation products in the aquatic environment.

34 Keywords: photolysis, photodegradation products, polycyclic hydrocarbons, fluorene, in vitro 35 tests 


\section{Introduction}

The industrial and urban development which occurred in the second half of the $20^{\text {th }}$ century allowed the emergence of thousands of organic chemicals into aquatic environment without prior study of their toxicity. Several decades later, a large number of these compounds have shown negative impacts on human health and ecosystems even at very low concentrations. Polycyclic Aromatic Hydrocarbons (PAHs) are among the most widespread pollutants in the environment. They are of special concern due to their negative characteristics, including persistence, mobility in the environment and toxicity. The most environmental PAHs result from incomplete combustion of organic matter: forest fires, automobile exhaust, coal, oil refining processes, etc. $\left[{ }^{1},{ }^{2},{ }^{3}\right]$ Many PAHs are toxic; their mainly adverse health effects are cancers in various tissues such as prostate, breast, pancreatic and cervical $\left[{ }^{4},{ }^{5},{ }^{6},\right]$, cardiovascular diseases $\left[{ }^{8}\right]$ and immunosuppression $\left[{ }^{9}\right]$. PAHs are also known to have endocrine disrupting capabilities with consequent alteration of fertility in terrestrial and aquatic organisms $\left[{ }^{10},{ }^{11},{ }^{12}\right]$. A number of PAHs are also found to bind the estrogen, androgen and aryl hydrocarbon receptors and either induce or inhibit the estrogen, antiandrogen and dioxin-like responses $\left[{ }^{13},{ }^{14},{ }^{15}\right]$. For these reasons, PAHs have been listed as priority pollutants by both the US Environmental Protection Agency (US EPA) and the European Union (EU). Despite a reduction in PAHs emissions from fuel combustion, resulting from the substitution of coal by fossil fuels since the 1960s and from the development of clean fuels and catalytic converters for diesel and gasoline engines in the recent years, the amounts of PAHs in aquatic environment remains high. ${ }^{[16]}$ PAHs can be introduced into the aquatic environment through different routes including industrial and municipal wastewater, rainwater runoff, atmospheric deposition and sediment- and air-water exchange $\left[{ }^{17},{ }^{18}, 16\right]$. The concentration of PAHs in aquatic environments varies widely depending on the nature of water (i.e. ground water versus surface water) and the sampling location. In European surface water, the concentrations of PAHs were reported to range from 0.6 to $171.3 \mathrm{ng} . \mathrm{L}^{-1}$ in rainwater $\left[{ }^{19},{ }^{20}\right]$, from 2 to $587 \mathrm{ng} . \mathrm{L}^{-1}$ in river water $\left[{ }^{21},{ }^{22}, 20\right]$, from 5 to $1930 \mathrm{ng} . \mathrm{L}^{-1}$ in seawater $\left[{ }^{23},{ }^{24}\right]$, from 1.4 to $5 \mathrm{ng} . \mathrm{L}^{-1}$ in lake and reservoir water [22,19] and from 4 to $1473 \mathrm{ng} . \mathrm{L}^{-1}$ in wastewater [22,20]. In natural water environment, the PAHs are eliminated mainly through processes of sorption to sediments, biodegradation and photodegradation. Photodegradation remains the main route of PAHs degradation, especially for the most recalcitrant ones. It has been reported that photolysis processes induced under 
natural sunlight can be significantly accelerated by dissolved organic matters. In advanced oxidation processes involving UV light for water and wastewater purification, the ultimate objective is to achieve complete mineralization of organic pollutants to carbon dioxide, water, or at least to produce small organic intermediates more soluble, readily biodegradable and thus less toxic than their parent compounds $\left[{ }^{25},{ }^{26},{ }^{27}\right]$. Numerous studies have been conducted on the photodegradation of PAHs. In most of these studies, much interest has been focused on the optimization of degradation conditions. The evaluation of the degradation efficiency only relies on the disappearance of the initial pollutants. In this way, the kinetics of disappearance are evaluated, as well as the monitoring of the mineralization rate achieved along the process. Unfortunately, in the course of the degradation of these pollutants, some by-products potentially more toxic and sometimes even more stable than the parent compounds may be formed $\left[{ }^{28},{ }^{29}\right]$. For example, studies carried out by Gala et al., Bertilsson et al., Shemer et al. and Woo et al. have shown that exposure to UV irradiation may increase the toxicity of many PAHs to a variety of aquatic organisms $\left[{ }^{30}, 25,{ }^{31}, 27\right]$. However, very little is known about the nature of the substances responsible for this increase in toxicity. In this regard, we were interested in the identification of the phototransformation by-products of PAHs. In the present study, fluorene (Flu) has been chosen as a model compound for several reasons. First, according to our knowledge, identification of photoproducts of this PAH in water has never been reported. Second, fluorene is one of the US EPA and EU priority PAHs because it has water solubility significantly higher than those of PAHs with larger molecular weights. Third, a previous study has shown that 2-hydroxyfluorene, which could be a possible photodegradation product of fluorene in water, exhibits estrogenic activity $\left[{ }^{32}\right]$. The primary objectives of the present research were the elucidation of the photoproducts chemical structures and that of the reaction pathways leading to their formation during UV-Vis irradiation of fluorene in aqueous solution. The kinetics of fluorene disappearance and those of appearance of some photoproducts were examined. In vitro bioassays based on human MELN and fish PLHC-1 cell lines were carried out to evaluate the estrogenic and dioxin-like potency of photoproducts for which chemical standards were commercially available. 


\section{Materials and methods}

\subsection{Chemicals, reagents and sample preparation}

Standards of fluorene (Flu, $\geq 99 \%$ purity), 2-hydroxyfluorene (2OH-Flu, $\geq 98 \%$ purity), 3hydroxyfluorene (3OH-Flu, $\geq 98 \%$ purity), 9-hydroxyfluorene ( $9 \mathrm{OH}-\mathrm{Flu}, \geq 96 \%$ purity), were purchased from Sigma-Aldrich (Saint-Quentin Fallavier, France). HPLC-grade methylene chloride (DCM), acetonitrile (ACN), methanol (MeOH), pyridine, dimethylsulfoxide (DMSO) and the silylation reagent: N,O-bis(trimethylsilyl)trifluoroacetamide (BSTFA) with $1 \%$ of trimethylchlorosilane (TMCS) were also purchased from Sigma-Aldrich (France). Ultrapure water used for photolysis experiments and SPE extraction was obtained by purification of drinking water using a Millipore Milli-Q device (resistivity < $18 \mathrm{M} \Omega . \mathrm{cm}$; DOC $<0.1 \mathrm{mg} . \mathrm{L}^{-1}$; Millipore, CA, USA). A stock solution of individual compounds: Flu, 2OH-Flu, 3OH-Flu and 9OH-Flu, each one at $10 \mu \mathrm{g} \cdot \mathrm{mL}^{-1}$, was prepared in amber vials by dissolving the appropriate amount of each chemical in anhydrous methylene chloride. It was used for the development of the GC-MS analytical method. All the standard chemicals were prepared in DMSO for bioassay testing.

\subsection{Irradiation device}

Photolysis experiments were conducted in a cylindrical pyrex glass reactor (200 mm long x 25 $\mathrm{mm}$ internal diameter, effective reaction volume: $50 \mathrm{~mL}$ ). This reactor is surmounted by two tubes closed by valves allowing constant pressure (1 atm), constant supply of oxygen and removal of the sample to be analysed. A UV lamp immersed in a cylindrical quartz water jacket tube was placed in the middle of the reactor. The lamp used in our experiments was a highpressure mercury vapour lamp (HPL-N 125W/542 E27 SG) manufactured from Philips-France (Ivry sur Seine, France). It emits a polychromatic radiation with wavelengths ranging from 350 $\mathrm{nm}$ to $750 \mathrm{~nm}$. Approximately $15 \%$ of the emitted light power is in the range $350-400 \mathrm{~nm}$ with a further $85 \%$ between 400 and $750 \mathrm{~nm}$. The luminous flux emitted from this lamp was reported by the manufacturer to be $6200 \mathrm{~lm}$. Prior to photolysis experiments, the lamp was allowed warming up for $10 \mathrm{~min}$ to achieve equilibrium intensity. Homogeneity of the reaction medium was carried out using a magnetic stirrer. During irradiation period, the reaction temperature was maintained between 23 and $25^{\circ} \mathrm{C}$ by adjusting the flow rate of cooling water. The reactor was wrapped in an aluminium foil to optimize UV-visible irradiation of the solution and to avoid emission outside the reactor. The control samples were continuously stirred and kept in the dark 
under similar experimental conditions as the irradiated solution. For photolysis experiments, a fluorene solution at $2 \mathrm{mg} . \mathrm{L}^{-1}$ was prepared by dissolving $1 \mathrm{mg}$ of fluorene standard in $500 \mathrm{~mL}$ of Milli-Q water. It was prepared just prior to use to reduce any possible biological, physical and/or chemical transformation due to prolonged storage of fluorene.

\subsection{Extraction of residual fluorene and its photoproducts}

Solid phase extraction (SPE) has been used to extract and enrich fluorene and its generated photoproducts from water solutions. The protocol employed derives from methods described in our previous studies. ${ }^{[33]}$ Briefly, Oasis ${ }^{\circledR}$ HLB cartridges (200 mg x 6 mL, Waters, France) were placed into a SPE vacuum manifold (Supelco, Bellefonte, PA, USA), conditioned with 3 $\mathrm{mL}$ of $\mathrm{ACN}$, then $3 \mathrm{~mL}$ of distilled water, and equilibrated with $3 \mathrm{~mL}$ of a mixture of methanol/water $(5: 95, \mathrm{v} / \mathrm{v})$. Sample volumes of $50 \mathrm{~mL}$ were loaded on the cartridges, and the aqueous solution was eluted as waste at a rate of approximately $2.5 \mathrm{~mL} \cdot \mathrm{min}^{-1}$. The retained compounds (fluorene and its photodegradation products) were eluted by loading four times 2.5 $\mathrm{mL}$ of methanol. The organic extracts were evaporated to complete dryness under a gentle nitrogen stream, and dry residues were resuspended in $0.5 \mathrm{~mL}$ of DCM, sonicated and then divided into two equal parts. The first one was completely dried under a gently stream of nitrogen and reconstituted into $50 \mu \mathrm{L}$ of DMSO for bioassay analysis. The second aliquot was subdivided again into two equal parts; the first one was directly analysed by GC/MS, while the second was derivatized with BSTFA according to the method already described by Kinani et al. prior to GC/MS analysis [33].

\subsection{GC-MS analysis}

Residual fluorene and generated photoproducts (derivatized and non-derivatized extracts) were analysed using a "450-GC" gas chromatograph equipped with a "CP-8400" autosampler and coupled to a "240-MS" ion trap mass spectrometer (Varian, Les Ulis - France). The chromatographic separation was performed on a $60 \mathrm{~m}$ "Factor four VF-10-MS" (10\% phenyl, 90\% methylpolysiloxane) capillary column (internal diameter: $0.25 \mathrm{~mm}$, film thickness: 0.25 $\mu \mathrm{m})$ from Varian. All experiments were performed by automatically injecting $1.0 \mu \mathrm{L}$ of sample in the splitless mode at a rate of $50 \mu \mathrm{L} . \mathrm{s}^{-1}$. High purity (99.999\%) helium was used as the carrier gas at a constant flow of $1.4 \mathrm{~mL} \cdot \mathrm{min}^{-1}$ hold by electronic pressure control. The injector temperature was set at $280^{\circ} \mathrm{C}$. The split valve opened after $2.0 \mathrm{~min}$, with a split ratio of $40 / 100$. The capillary column was ramped from an initial temperature of $50{ }^{\circ} \mathrm{C}$, held for $0.5 \mathrm{~min}$, at 10 ${ }^{\circ} \mathrm{C} . \mathrm{min}^{-1}$ up to $320^{\circ} \mathrm{C}$ where it was held for $7.5 \mathrm{~min}$. The total duration of GC analysis was 35.0 
$160 \mathrm{~min}$. The manifold, ion trap electrodes and transfer line temperatures were set at $120{ }^{\circ} \mathrm{C}, 220$

$161{ }^{\circ} \mathrm{C}$ and $300{ }^{\circ} \mathrm{C}$, respectively. The mass spectrometer was operated in internal ionization source 162 and the acquisition was performed in full scan mode. Both chemical ionization (CI) and electron 163 ionization (EI) modes were used for a reliable structural elucidation of photodegradation 164 products of fluorene. The instrument was automatically tuned using the ions resulting from 165 electron ionization of perfluorotributylamine. In EI, the ionization energy was $70 \mathrm{eV}$ and the 166 filament current was $10 \mu \mathrm{A}$. Spectra were recorded using the automatic gain control (AGC) 167 function with a target value of 20.000. CI was performed using methanol as reagent gas. 168 Automatic reaction control (ARC) parameters were $100 \mu \mathrm{s}$ for the maximum ionization time, 169 and 2000 for the target value. In all experiments, the multiplier voltage was set to $1850 \mathrm{~V}\left(10^{5}\right.$ 170 gain) by automatic tuning. Ions were scanned over a $50-600 \mathrm{~m} / \mathrm{z}$ range, with a scan rate of 1 171 scan. $\mathrm{s}^{-1}$. For the experiments carried out with fluorene at $0.1 \mathrm{ppm}$ in raw lake water (see section 172 3.3), GC-MS analyses were performed with the same chromatographic conditions, using 173 selected ion storage in the EI mode. The two major ions (see Table 1) were selected for each 174 compound. The sensitivity was also enhanced by increasing the filament current and multiplier 175 voltage values up to $50 \mu \mathrm{A}$ and $2000 \mathrm{~V}$, respectively.

\subsection{In vitro bioassays}

178

180

181

182

183

184

\subsubsection{Estrogenic activity}

The MELN reporter cell line has been used in order to assess the estrogenic activity of commercially available photoproducts of fluorene. This cell line was obtained by stable transfection of MCF-7 human breast cancer cells by an ERE-bGlob-Luc-SVNeo plasmid [ $\left.{ }^{34}\right]$. The cells were routinely cultured in phenol red containing Dulbecco's Modified Eagle's Medium (DMEM), supplemented with 5\% foetal calf serum (FCS), 1\% nonessential amino acids and penicillin/streptomycin $\left(50 \mathrm{U} / \mathrm{mL}\right.$ each) in a $5 \% \mathrm{CO}_{2}$ humidified atmosphere at 37 ${ }^{\circ} \mathrm{C}$. For experiments, cells were left to incubate for 2 days in phenol red free DMEM supplemented with 3\% dextran charcoal coated-FCS (DCC medium) before seeded in white opaque 96-wells culture plates at a density of 50,000 cells per well. Serial dilutions of reference or test chemicals were added in triplicates $24 \mathrm{~h}$ later and then left to incubate for $16 \mathrm{~h}$. In all assays, DMSO in the culture medium was always at $0.1 \% \mathrm{v} / \mathrm{v}$, including in cell controls. At this concentration, no effect on cell viability or luciferase activity was observed. After cell exposure, 
191 the medium was removed and replaced by $50 \mu \mathrm{L}$ of DCC medium containing $0.3 \mathrm{mM}$ of D-

192 luciferin and the luminescence signal was measured in living cells for $2 \mathrm{~s}$ per well with a

193 microtiter plate luminometer ( $\mu$ Beta, Wallac). Relative luminescence units (RLU) were

194 converted to relative response units expressed as percent of maximal luciferase activity induced

195 by the positive control (17ß-Estradiol (E2) at $10 \mathrm{nM})$.

196 2.5.2 Dioxin-like activity

197 The dioxin-like activity was monitored by using the fish hepatic PLHC-1 cell line (ATCC,

198 \#CRL-2406) as described by Louiz et al. [15]. The cells were routinely grown at $30^{\circ} \mathrm{C}$ in E-

199 MEM culture media supplemented with $10 \%$ FCS and $1 \%$ antibiotics in a $5 \% \mathrm{CO}_{2}$ humidified

200 atmosphere. For experiments, cells were seeded in 96-well plates at a density of approximately

20150,000 cells per well. After $24 \mathrm{~h}$ of incubation, cells were exposed to test chemicals or sample

202 extracts for $4 \mathrm{~h}$ incubation period. Then, plates were processed for 7-ethoxyresorufin-O-

203 deethylase (EROD) activity in intact cells, as previously described ${ }^{[15]}$ Results were expressed

204 as percent of EROD activity induced by the positive control (tetrachlorodibenzodioxin (TCDD)

205 at $0.3 \mathrm{nM})$.

$206 \quad 2.5 .3$ Cytotoxicity

207 The ability of test chemicals to alter cell viability after a 24 h-exposure was assessed in the

208 PLHC-1 cell line by using the MTT assay $\left[{ }^{35}\right]$, as previously described $\left[{ }^{36}\right]$. The results were 209 expressed as relative to DMSO treated control cells.

\section{3. Results and discussion}

\subsection{Identification of fluorene photoproducts by GC-MS}

212 The comparison between chromatograms of irradiated and non-irradiated solutions of fluorene

213 revealed the presence of twenty six photoproducts. The identified compounds are summarized

214 in Table 1. Among the twenty six compounds, those which were commercially available, such 215 as 9-fluorenone, 2-hydroxyfluorene (2OH-Flu), 3-hydroxyfluorene (3OH-Flu) and 9216 hydroxyfluorene (9OH-Flu), were quickly and unambiguously identified by comparing 217 retention times and mass spectra with those of reference compounds. The other compounds 218 were identified on the basis on their EI and CI mass spectra interpretation. BSTFA 219 derivatization was helpful since it permitted to establish the number of exchangeable hydrogen 220 atoms for each photolysis product. 
222 Six products with $\mathrm{M}=182$ were detected with close retention times (ranging from 25.7 to 29.3 223 min.) and identical mass spectra. Compared to fluorene mass weight, those compounds are 224 shifted by +16 amu, suggesting addition of an oxygen atom. In derivatized extracts, the 225 corresponding molecular and pseudo molecular ions are shifted by +72 amu (one hydrogen 226 atom replaced by $\left.\mathrm{Si}\left(\mathrm{CH}_{3}\right)_{3}\right)$ in $\mathrm{EI}$ and $\mathrm{CI}$, leading to the conclusion that these compounds are 227 hydroxylated derivatives of fluorene $(\mathrm{OH}-\mathrm{Flu})$. Owing to the analysis of standard solutions, the 228 chromatographic peaks at 26.4, 26.5 and 29.1 were unambiguously attributed to, 9OH-Flu, $2292 \mathrm{OH}-\mathrm{Flu}$ and $3 \mathrm{OH}-\mathrm{Flu}$, respectively, and both other peaks were logically assumed to 230 correspond to 1-hydroxyfluorene (1OH-Flu) and 4-hydroxyfluorene (4OH-Flu).

231 A product is detected at $26.5 \mathrm{~min}$. Its main ions in EI are $\mathrm{m} / \mathrm{z} 180$ and m/z 152, corresponding 232 to the molecular ion $\mathrm{M}^{+}$and to $[\mathrm{M}-\mathrm{CO}]^{+}$, respectively. The EI and CI mass spectra and the 233 retention time of this product were consistent with those observed for the authentic standard of 234 9-fluorenone. This result suggests that a $\mathrm{CH}_{2}$ group of fluorene has been oxidized into $\mathrm{CO}$, as 235 depicted in Figure 1. A similar oxidation was reported by Rivas et al. who proposed a detailed 236 mechanism of oxidation of fluorene by hydroxyl radicals. 9-fluorenone, 9-fluorenol and 237 dibenzofuran were formed during the first step of the reaction; further oxidation of these 238 products proceeded via hydroxylation and cleavage of the fluorene ring $\left[{ }^{37}\right]$.

Figure 1

240 Nine products with $\mathrm{M}=196$ were detected. They were divided into two groups on the basis of 241 their EI mass spectra. The four first eluted compounds (27.8, 29.8, 31.8 and 31.9 minutes) 242 correspond to isomers of hydroxyfluorenone (OH-Flu-one): EI mass spectra of some isomers 243 of OH-Flu-one are displayed in the NIST mass spectra database $\left[{ }^{38}\right]$. These spectra are identical 244 so that the different isomers could not be determined owing to the database. It is to be noted 245 that 2-benzyl-1,4-benzoquinone provides the same EI mass spectrum [38]. Its formation has 246 been considered since 1,4-naphtoquinone was detected as a photolysis product of naphthalene 247 in several previous studies $\left[{ }^{39},{ }^{40}\right]$. In the present work, BSTFA derivatization of the compounds 248 of interest led to the addition of one trimethylsilyl (TMS) group to each compound (M=268), 249 showing the presence of one exchangeable hydrogen atom, in agreement with OH-Flu-one 250 isomers. The five other products with $\mathrm{M}=196$ ( $\mathrm{RT}=30.1,30.2,30.3,30.4$ and 30.5 minutes) 251 displayed EI mass spectra with ions at m/z 178, m/z 166 and m/z 165, resulting from 
eliminations of $\mathrm{H}_{2} \mathrm{O}, \mathrm{H}_{2} \mathrm{C}=\mathrm{O}$ and $\mathrm{CH}_{3} \mathrm{O}$, respectively. After many attempts to find likely

253 chemical structures corresponding to $\mathrm{C}_{13} \mathrm{H}_{8} \mathrm{O}_{2}$, we finally concluded that the only possibilities corresponding to these EI mass spectra were structures of fluorene methanol (MeOH-Flu), in agreement with the solution suggested by the NIST database. Since photolysis had been performed in pure water, the only explanation for the addition of a carbon atom to Flu was through the formation of a dimer species, for which a mechanism of formation is proposed in Figure 2. The first eluted isomer $(\mathrm{RT}=30.1 \mathrm{~min}$.) was determinated to be $9 \mathrm{MeOH}-\mathrm{Flu}$. As a matter of fact, its EI mass spectrum displays a m/z 178 ion (loss of $\mathrm{H}_{2} \mathrm{O}$ from $\mathrm{M}^{+}$) in greater abundance than for other isomers ( $82 \%$ vs $24 \%$ ). The supporting information file SI-1 shows the dissociation pathways proposed to interpret the EI mass spectrum of 9MeOH-Flu. The easier loss of water from $9 \mathrm{MeOH}-\mathrm{Flu}$ than for other $\mathrm{MeOH}$-Flu isomers is easily rationalized on the basis of the $\alpha, \beta$ concerted elimination of $\mathrm{H}_{2} \mathrm{O}$ involving a hydrogen atom of the sp3 carbon, which cannot occur for other isomers.

\section{Figure 2}

Four compounds with $\mathrm{M}=348$ were detected. The first one elutes at $37.1 \mathrm{~min}$. while the three other ones are coeluted between 38.4 and 38.6 minutes. All are assumed to be isomers of hydroxylated dimers of fluorene. Their formation is discussed below. Five products with $\mathrm{M}=$ 198 were detected, one eluted at $28.5 \mathrm{~min}$. and three between 31.2 and $31.6 \mathrm{~min}$. For the first one, the EI mass spectra obtained from non-derivatized extracts showed major fragment ions at $\mathrm{m} / \mathrm{z} 181\left([\mathrm{M}-\mathrm{OH}]^{+}\right)$and $\mathrm{m} / \mathrm{z} 153\left([\mathrm{M}-\mathrm{COOH}]^{+}\right)$, issued from characteristic losses for compounds containing a carboxylic group. In chemical ionization, this molecule exhibits a base peak at m/z 181 consistent with water elimination. The EI mass spectrum obtained from derivatized extracts exhibits a molecular ion at $\mathrm{m} / \mathrm{z} 270$ and a $\mathrm{MH}^{+}$pseudo molecular ion at $\mathrm{m} / \mathrm{z}$ 271 issued from auto protonation, a phenomenon classically observed in ion trap mass spectrometers. The major fragment ions are observed at m/z $181\left[\mathrm{M}-\mathrm{OSi}\left(\mathrm{CH}_{3}\right)_{3}\right]^{+}, \mathrm{m} / \mathrm{z} 153$ $\left[\mathrm{MH}-\mathrm{HOSi}\left(\mathrm{CH}_{3}\right)_{3}-\mathrm{CO}\right]^{+}$and $\mathrm{m} / \mathrm{z} 73\left[\mathrm{Si}\left(\mathrm{CH}_{3}\right)_{3}\right]^{+}$. The main ions of the $\mathrm{CI}$ mass spectrum are $\mathrm{m} / \mathrm{z} 271\left(\mathrm{MH}^{+}\right)$and $\mathrm{m} / \mathrm{z} 181$ corresponding to $\left[\mathrm{MH}-\mathrm{HOSi}\left(\mathrm{CH}_{3}\right)_{3}\right]^{+}$. Based on these mass fragmentation patterns and on the results of MS databases researches, this compound was identified as 2-biphenylcarboxylic acid (BPCA). Two mechanisms can be advanced to explain the formation of this compound. The first one involves direct oxidation of fluorene while the second one involves oxidation of 9-fluorenone, which has been previously identified as a photoproduct of fluorene. The four other compounds with $\mathrm{M}=198$ may correspond either to 
dihydroxyfluorene congeners, either to structures such as those displayed in the supporting information file SI-2, which are dialdehydes analoguous to those reported by several authors in their studies devoted to photocatalysis of naphthalene $\left[39,{ }^{41},{ }^{42}\right]$. The molecular weight of these three compounds is shifted to $\mathrm{M}=342$ after BSTFA derivatization, thus indicating that two exchangeable hydrogen atoms were replaced by a TMS group and allowing to conclude in favor of dihydroxyfluorene congeners.

\section{3-2 Mechanistic approach of the photodegradation of fluorene}

As demonstrated in what follows, the sp3 carbon atom of fluorene leads to a particular behavior under UV-Vis irradiation in comparison with other PAHs. As a matter of fact, one of the main mechanisms generally proposed to rationalize oxidation of PAHs under UV photolysis begins by the formation of a radical molecular cation from the irradiated molecule through electron removing $\left[{ }^{43}\right]$. The solvated electron released by the molecule is assumed to be transferred to dissolved oxygen yielding a superoxide anion which may, in turn, react with water to provide $\mathrm{H}_{2} \mathrm{O}_{2}$ (see the upper left side of Figure 1). UV photolysis of $\mathrm{H}_{2} \mathrm{O}_{2}$ yields hydroxy radicals $\left[{ }^{44}\right]$. The mechanism of electron removing in the aqueous phase may be compared with that of electron ionization in the gas phase, which is widely used in mass spectrometry. $\Pi$ electrons are known to be much more easier to abstract than $\sigma$ electrons. That is why ionization is expected to occur on one of the aromatic rings, as observed in mass spectrometry. In this study, ionization on one of both aromatic rings can easily account for the formation of 1-, 2-, 3- and 4hydroxyfluorene (Figure 1, left pathway) but cannot lead to the formation of 9-hydxoxyfluorene (9OH-Flu) and fluorenone (Flu-one). The detection of large amounts of 9OH-Flu and Flu-one suggests a mechanism, competing with electron removing, consisting in the direct cleavage of one of the $\mathrm{C}-\mathrm{H}$ bonds in which the sp3 carbon atom is involved, as suggested in the center pathway of Figure 1. In the present case, the elimination of $\mathrm{H}^{\cdot}$ from this carbon atom leads to a fully conjugated radical which is particularly stable. A direct reaction between this radical and a $\mathrm{HO}$ radical leads to $9 \mathrm{OH}-\mathrm{Flu}$ but also to other hydroxyfluorene isomers because of mesomeric effects. We suggest that fluorenone results from dehydrogenation of fluorenol as the "kinetic" 311 approach (see below) shows a good correlation between the increase in Flu-one concentration 312 and the decrease in 9OH-Flu concentration. Furthermore, we observed when analyzing standard 313 samples that 9OH-Flu is spontaneously converted into Flu-one in a few hours, at ambient 314 temperature, even sheltered from light. It is to be noted that in a previous study, Dabrowska et 315 al. established that the formation of fluorenone precedes that of fluorenol when irradiating 
316 fluorene not in water but in methylene chloride and hexane $\left[{ }^{45}\right]$. Sabaté et al. reached the same conclusion performing irradiation in an ethanol/water mixture $\left[{ }^{46}\right]$. Both studies focused on the stability of fluorene under photolysis and only Flu, OH-Flu and Flu-one were detected owing to a UV-vis spectrophotometer; other by-products were not detected or not considered. The formation of BPCA is assumed to result from oxidation of Flu-one through addition of a hydroxy radical. Since dihydroxyfluorene (diOH-Flu) isomers could not be identified, their formation has been assumed to result from a hydroxy radical addition onto $9 \mathrm{OH}-\mathrm{Flu}$ and/or onto another $\mathrm{OH}-\mathrm{Flu}$ isomer. Finally, the formation of hydroxy-9-fluorenone may result either from dehydrogenation of hydroxy-9-fluorenol, via a mechanism analogous to that involved in the reduction of $9 \mathrm{OH}-\mathrm{Flu}$ into Flu-one, either from attack of a hydroxy radical onto the later.

We proposed the mechanism displayed in Figure 2 to rationalize the formation of 9MeOH-Flu through a dimer intermediate. The formation of other MeOH-Flu isomers with the $\mathrm{CH}_{2} \mathrm{OH}$ group bound to an aromatic ring in 1,2,3 or 4 position can be explained with analogous mechanisms considering a dimer with a $\mathrm{C}-\mathrm{C}$ bond between the sp3 carbon atom and a carbon atom of an aromatic ring (Reaction pathways are suggested in the supplementary information file SI-3). The detection of biphenylene $(\mathrm{M}=152)$ at $18.0 \mathrm{~min}$. is in agreement with the suggested mechanism.

With the aim to establish how photolysis products of Flu are related to each other and if the evolutions of relative amounts are in agreement with the proposed reaction pathways, we followed relative concentrations as a function of the irradiating time up to 120 minutes. A "real" kinetic study was not the purpose of its work; it would have required possessing standard compounds for all the photolysis products and would have been very complicated to achieve since several photolysis pathways are undoubtedly in competition. Given the unexpected evolution of the fluorene concentration as a function of the irradiation time, kinetics experiments were carried out three times and provided results with a good repeatability (RSD $<15 \%$ )". Figure 3 displays the evolution of the relative amounts of fluorene and its photoproducts. Since concentrations of isomeric compounds undergo the same evolution, sums of amounts were plotted for much clarity. It is to be noted that the amounts reported in figure 3 correspond to the areas of chromatographic peak integrated on the total ionic current (TIC) in the EI mode and normalized to the initial TIC value which corresponds to the fluorene peak area at $\mathrm{t}_{0}$. Considering the likely differences in response factors between compounds, the relative amounts plotted allow the monitoring of a given photoproduct but they cannot be used to compare concentrations of different photoproducts. 
349 The concentration of Flu decreases by a factor four during the first fifteen minutes of irradiation,

350 then increases until one hour of irradiation and decreases again during the following hour.

351 Figure 3 shows evidence that the fast decrease in Flu concentration corresponds to dimers

352 formation. Dimers partially dissociate in turn to give biphenylene and $\mathrm{MeOH}-\mathrm{Flu}$ isomers,

353 which are assumed to eliminate $\mathrm{CH}_{2} \mathrm{OH}$ radicals under irradiation to provide fluorene again

354 (Figure 2), thus explaining the increasing relative amount of Flu after the first fifteen minutes

355 of irradiation. In competition with this reaction pathway, the mechanisms suggested in Figure

3561 appear to be slower. The kinetics features are in good agreement with the proposed

357 mechanisms since the concentrations in Flu-one and BCPA increase as that in 9OH-Flu 358 decreases. Amounts of diOH-Flu isomers increase then slowly decrease as those of $\mathrm{OH}-\mathrm{Flu}$ 359 isomers increase.

Figure 3

\subsection{Irradiation in more realistic conditions}

362 The above experiments were performed with a relatively high concentration of fluorene to allow 363 fullscan detection in GC-MS and thus characterization of photoproducts. To get closer of 364 natural conditions, additional experiments were carried out with organic matter containing 365 water taken from Lake Palaiseau (France) spiked with fluorene at $100 \mu \mathrm{g} . \mathrm{L}^{-1}$. Water evaporation 366 under mild conditions led to a dry matter residue of $230 \mathrm{mg}^{-1} \mathrm{~L}^{-1}$. Experiments were conducted 367 with irradiation times of 60 and $120 \mathrm{~min}$. The sample preparation process was almost the same 368 as the one described in section 2.3; a filtration step on a PTFE membrane (diam. $13 \mathrm{~mm}$, pore size: $0.45 \mu \mathrm{m}$, Sigma-Aldrich, France) has only been added to remove suspended matter prior to solid phase extraction. GC-MS analyses were performed with the chromatographic 371 conditions previously described but using selected ion storage in the EI mode. The two major 372 ions (see Table 1) were selected for each compound; the method sensitivity was enhanced by 373 increasing both filament current and electron multiplier voltage (see section 3.2). For both 374 irradiation times, the GC-MS chromatograms showed the photoproducts characterized earlier 375 but those at $\mathrm{M}=348$, which were assumed to result from dimerization and hydroxylation of 376 fluorene and those at $\mathrm{M}=196$ corresponding to methanol-fluorene congeners. The 377 disappearance of dimerized species using a solution at $0.1 \mathrm{ppm}$ may be easily explained as the 378 probability of reaction between two molecules decreases when the concentration decreases. 379 Non-detection of methanol-fluorene congeners is logical as well, given that their formation 380 requires a first dimerization step (see the mechanisms depicted in figure 1 and supporting 
information file 3). Additional experiments were performed in the fullscan mode, with the aim to possibly detect photoproducts issued from photo-induced reactions between fluorene and some components of dissolved organic matter. None was detected, either because such reactions do not occur or, more likely, because detection in the fullscan mode provides too high detection thresholds in comparison with the expected concentration ranges for such products.

\subsection{In vitro activity of hydroxyfluorenes}

Amongst all the identified degradation products, 2OH-Flu, 3OH-Flu and 9OH-Flu were commercially available as chemical standards and could thus be tested for their biological activity using in vitro cell-based assays. While none of the test compounds was found to alter cell viability at concentrations up to $100 \mu \mathrm{M}$ (data not shown), two of them, i.e. $2 \mathrm{OH}-\mathrm{Flu}$ and 3OH-Flu, were able to activate the estrogen (ER) and aryl hydrocarbon (AhR) receptors. As shown in Figure 4, 2OH-Flu and 3OH-Flu exerted a significant estrogenic activity in the MELN cell line, yielding up 50\% and 100\% of luciferase induction, respectively. For both chemicals, the EC50 was found to be $10 \mu \mathrm{M}$. Conversely, the parental compound fluorene was only weakly estrogenic (weak effect at $>30 \mu \mathrm{M}$ ) while $9 \mathrm{OH}-\mathrm{Flu}$ was not active at the test concentrations. The in vitro estrogenic activity of $2 \mathrm{OH}-\mathrm{Flu}$ has been previously reported in yeast-based assays $\left[{ }^{47},{ }^{48}\right]$, we confirm here its activity in a mammalian cell-based assay and report for the first time the estrogenic potency of $3 \mathrm{OH}-\mathrm{Flu}$. In addition, the position of the hydroxyl group on the molecule has a strong influence on the biological activity. Both 3OH-Flu and 2OH-Flu have a phenol ring in their structure which confers structural similarity with the endogenous hormone 17ß-estradiol and thus contributes to their ability to bind to and activate the ER [48]. Conversely, 9OH-Flu, which has no phenolic group in its structure, was unable to activate the ER in our assay.

\section{Figure 4}

Interestingly, 2OH-Flu and 3OH-Flu were also potent inducers of EROD activity in the PLHC1 cell line (Figure 5), with EC50s around 10 and $3 \mu \mathrm{M}$, respectively. This induction was marked after 4 hours of cell exposure but it was strongly reduced after $24 \mathrm{~h}$, only a weak induction (i.e. $10 \%$ that of the positive control) remaining at that time point. Similar patterns of transient EROD induction were previously reported with weakly persistent AhR agonists such as various 
411 PAHs, which suggested that the compounds were metabolized by cellular systems $\left[{ }^{49}, 15\right]$.

412 Fluorene and 9OH-Flu were found weakly or non-active in this bioassay.

414 Overall, our results indicate that Flu photolysis could generate hydroxylated degradation 415 products that are biologically much more active than is the parent compound. Further 416 experiments assessing the biological activity of photolyzed aqueous solutions of fluorene will 417 be necessary to characterize the whole toxicity of the mixture of photoproducts and thus to 418 provide a more comprehensive identification of active fluorene by-products. For instance, the 419 use of effect-directed analysis approach (EDA) $\left[{ }^{50}\right]$, e.g. based on HPLC fractionation of the 420 chemical mixture and chemical identification of bioactive fractions could nicely provide new 421 information on active photoproducts. $\left.{ }^{51}\right]$ Such approach has already proven useful to identify 422 phototransformation products of key emerging aquatic pollutants such as diclofenac $\left[{ }^{52}\right]$ or 423 estrone $\left[{ }^{53}\right]$. Identifying biologically active oxygenated PAHs using EDA would doubtless 424 provide crucial basic knowledge that is still needed, for instance, to better interpret estrogenic 425 and dioxin-like activities of PAHs-associated fractions in environmental complex samples.

\section{Conclusion}

Studies aiming to identify transformation products of pollutants are necessary to understand their behavior and impact on the environment, as well as their effects on human health. In the present work, the photodegradation of fluorene (Flu) under UV-Vis irradiation in water was investigated. The complete mineralization of Flu was not observed under our conditions. Using gas chromatography coupled with mass spectrometry, twenty-six photoproducts were characterized, mainly on the basis of electron and chemical ionization mass spectra interpretation. The main generated transformation products are monohydroxy derivatives.

435 Some secondary photoproducts were also observed: fluorenone, hydroxy fluorenone, 2436 biphenyl carboxylic acid, biphenylene, methanol fluorene congeners and hydroxy fluorene 437 dimers. Structural elucidation of photoproducts led to suggest photodegradation pathways.

438 Fluorene and the main photoproducts for which chemical standards were commercially available were tested for their ability to elicit cytotoxic, estrogenic and dioxin-like activity by using in vitro cell-based bioassays. None of the tested compounds was cytotoxic at 
441 concentrations up to $100 \mu \mathrm{M}$. However, 2-hydroxyfluorene and 3-hydroxyfluorene exerted 442 significant estrogenic and dioxin-like activity on a concentration range of 3-30 $\mu \mathrm{M}$. This study 443 demonstrates that UV-Vis irradiation of fluorene generates hydroxylated photoproducts that are 444 biologically much more active than is the parent compound and strengthens the need to consider 445 transformation products and not only identified pollutants in the environment. 446 


\section{$448 \quad$ Figure captions}

449 Figure 1. Reaction pathways proposed for the oxidation of fluorene under UV-Vis irradiation 450 in water. BPCA: Biphenyl carboxylic acid.

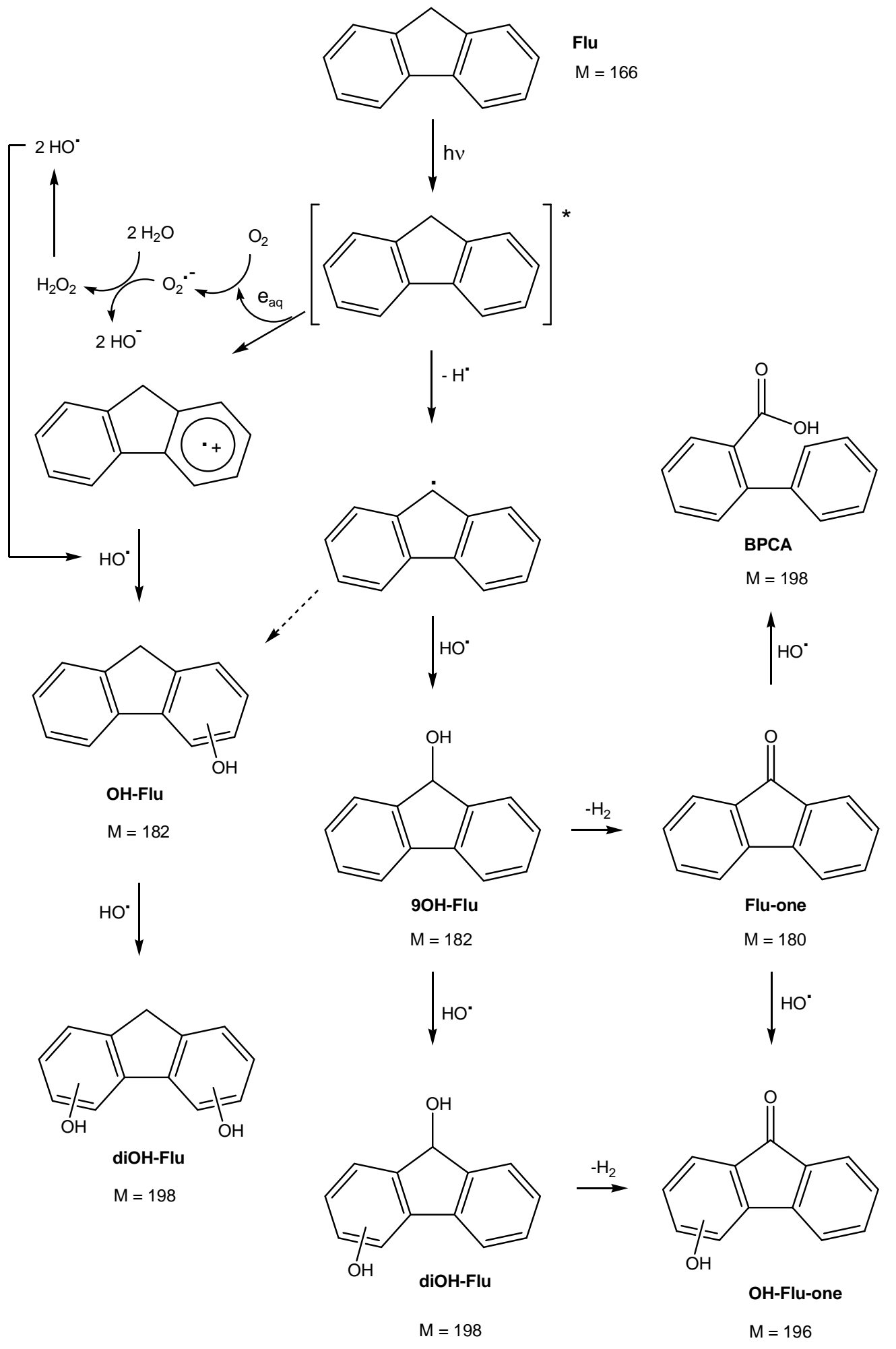


452 Figure 2. Reaction pathways proposed for the formation of $\mathrm{OH}-\mathrm{diFlu}$ dimers and $9 \mathrm{MeOH}-\mathrm{Flu}$ 453 under UV-Vis irradiation in water

454 Figure 2. The relative amounts reported correspond to the areas of chromatographic peak 455 integrated on the total ionic current (TIC) in the EI mode and normalized to the initial TIC 456 value which corresponds to the fluorene peak area at $t_{0}$. 
2<smiles>CC(C)CCCCCCCCc1ccccc1-c1ccccc1</smiles><smiles>c1ccc2c(c1)-c1ccccc1C2C1c2ccccc2-c2ccccc21</smiles><smiles>CCC</smiles><smiles>c1ccc2c(c1)-c1ccccc1C2C1c2ccccc2-c2ccccc21</smiles>

$\downarrow \mathrm{HO}^{\circ}$<smiles>OC(C1c2ccccc2-c2ccccc21)C12C=CC=CC1c1ccccc12</smiles><smiles>CCC(O)C1c2ccccc2-c2ccccc21</smiles>

$\leftarrow$ hv

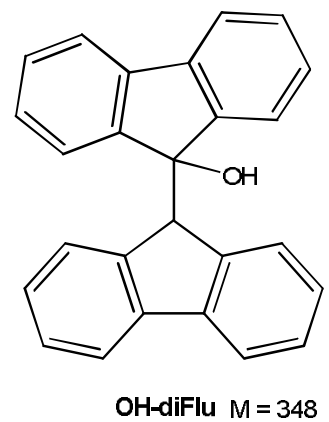

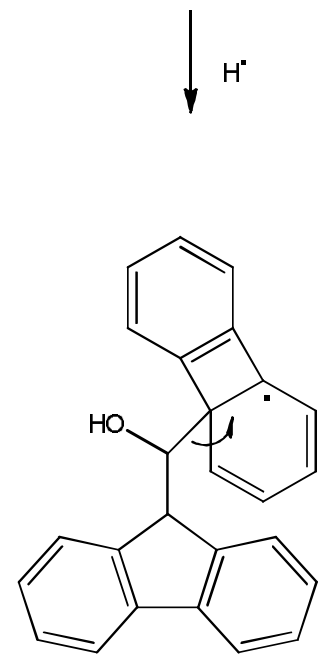<smiles>[Y16]c1ccccc1-c1ccccc1-c1ccccc1</smiles><smiles>CCC(C)=COCCOc1ccccc1</smiles><smiles>[CH]1c2ccccc2-c2ccccc21</smiles>

$\mathrm{H}^{*}$ 
462 Figure 3. Relative amounts of fluorene photoproducts as a function of the irradiation time.

463 Upper part involves photoproducts displayed in Figure 1while lower part involves those in

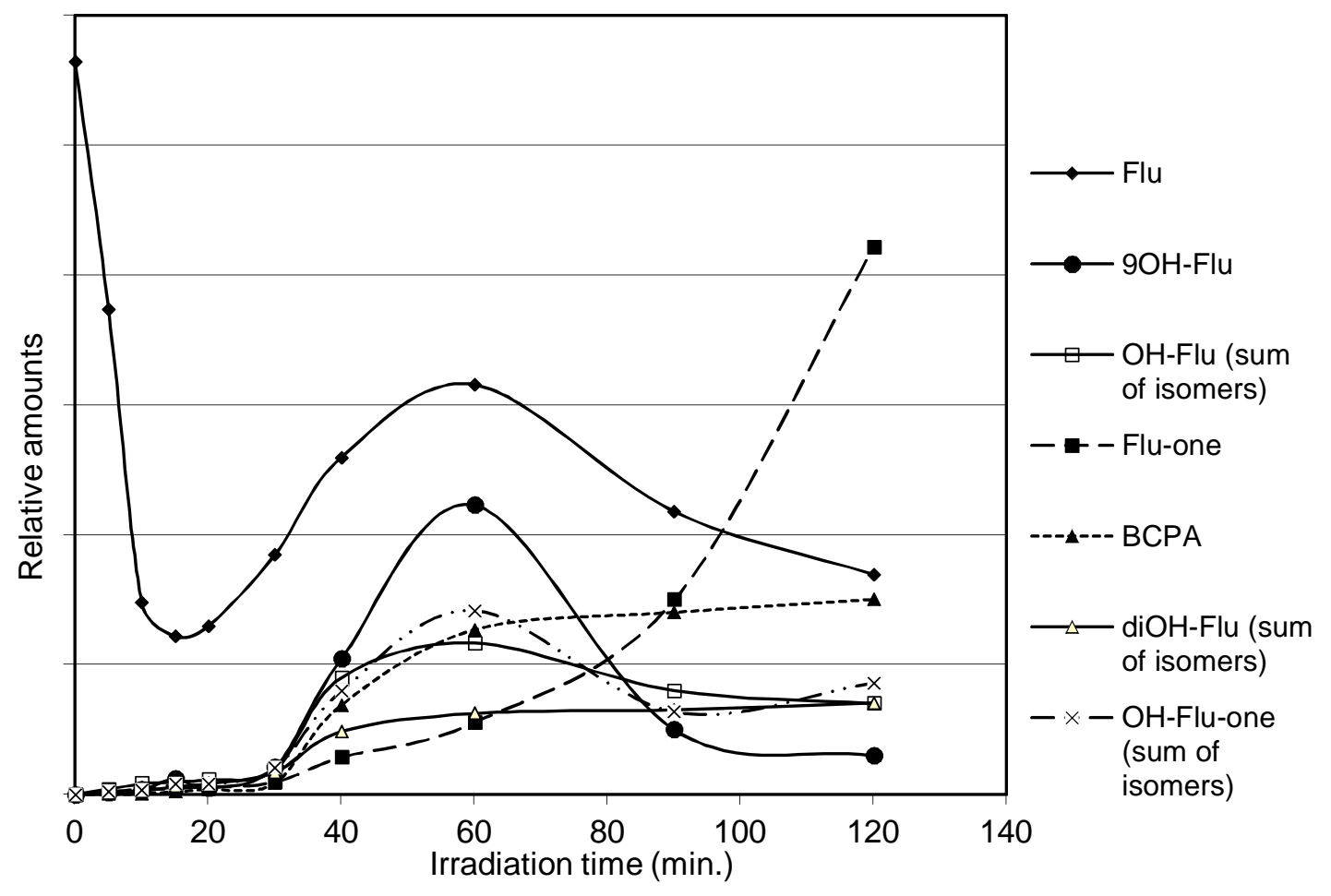

464

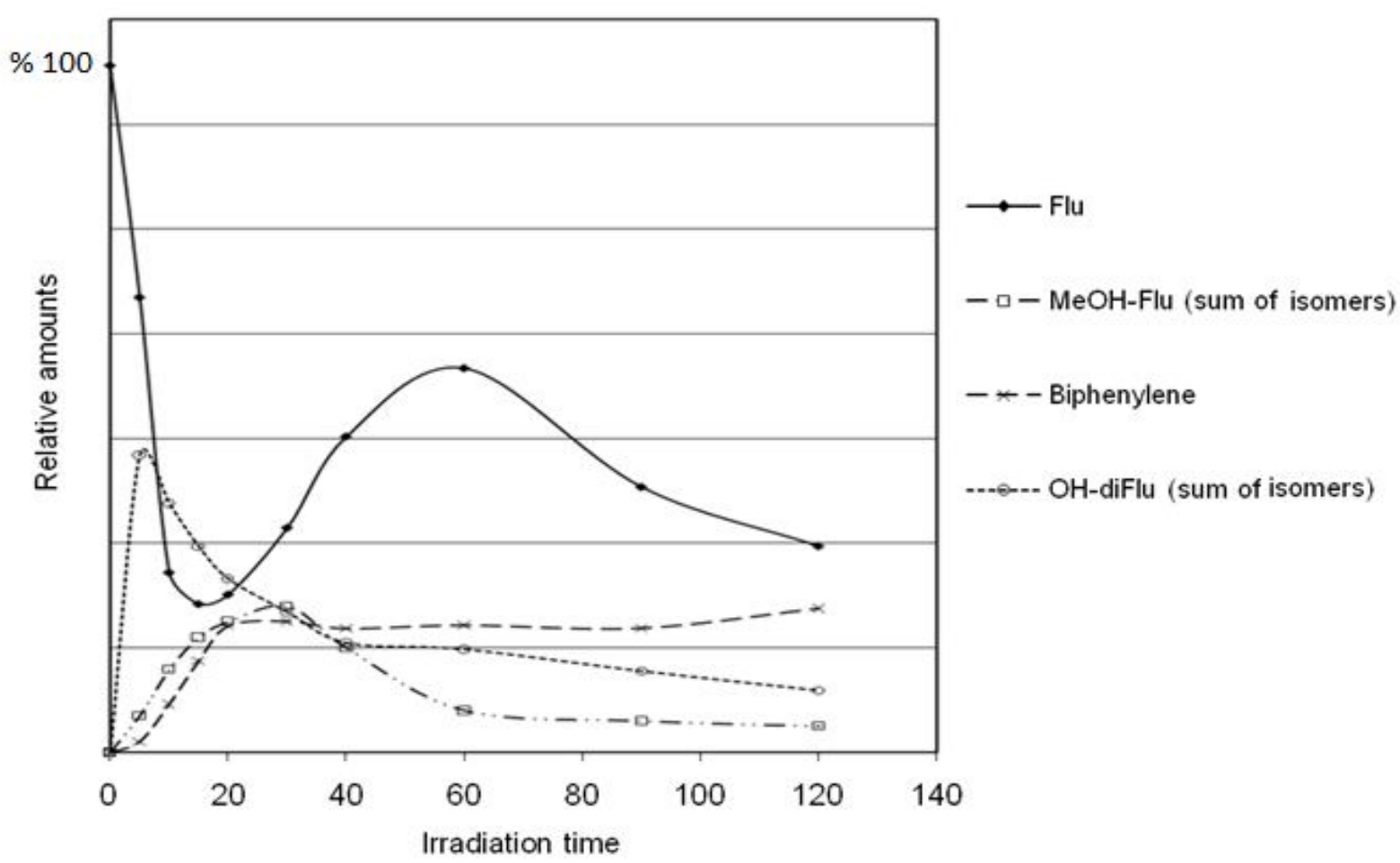


467 Figure 4. In vitro estrogenic activity of Flu, 2OH-Flu, 3OH-Flu and 9OH-Flu in the MELN 468 reporter cell line. Results are expressed as \% of luciferase induction relative to the positive 469 control estradiol (E2, $10 \mathrm{nM})$

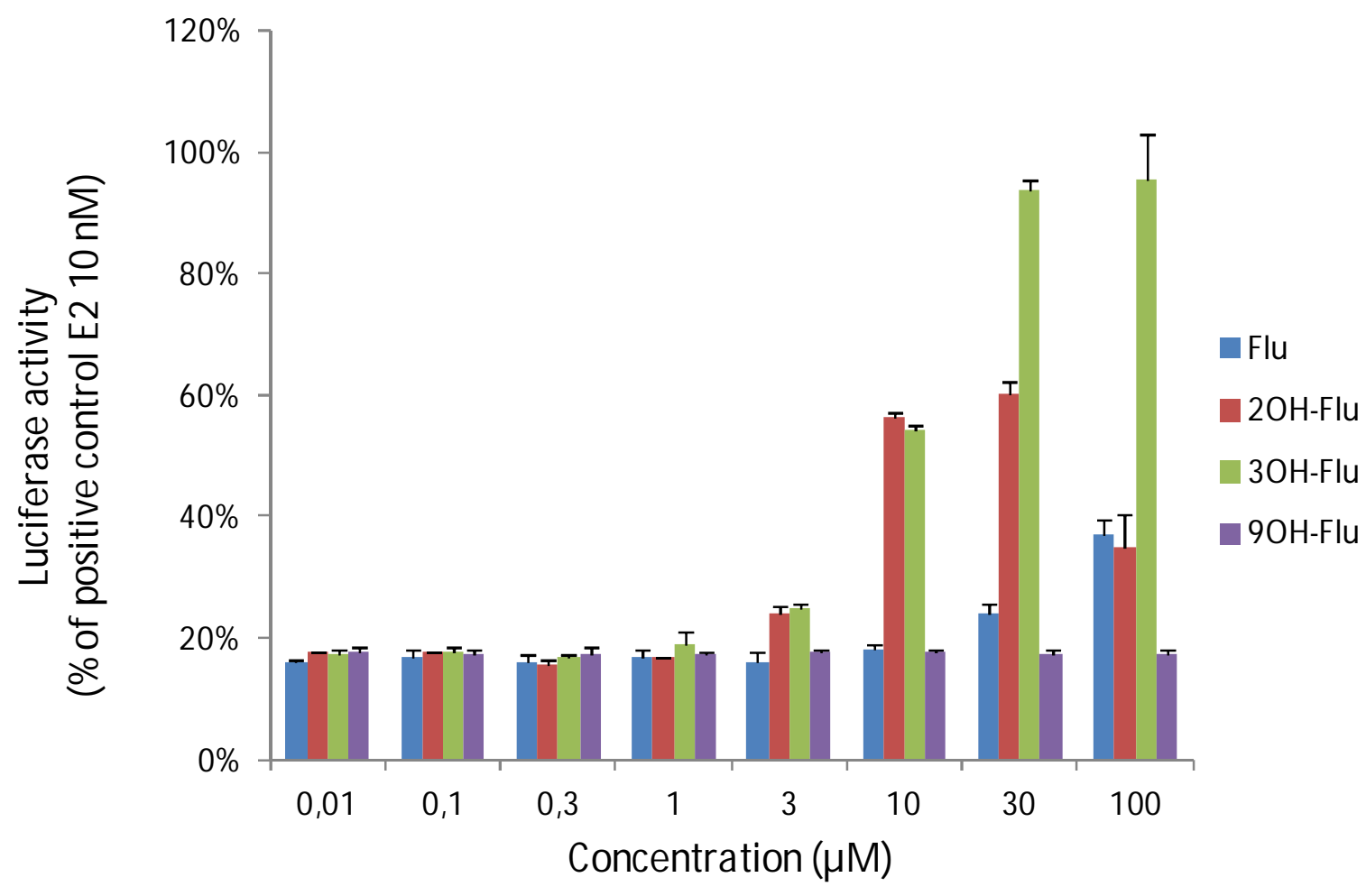

471 Figure 5. In vitro dioxin-like activity of Flu, 2OH-Flu, 3OH-Flu and 9OH-Flu in the PLHC-1 472 cell line after cell exposure for a) $4 \mathrm{~h}$ and b) $24 \mathrm{~h}$. Results are expressed as \% of EROD activity 473 induction relative to the positive control dioxin (TCDD, $0.3 \mathrm{nM}$ ) 

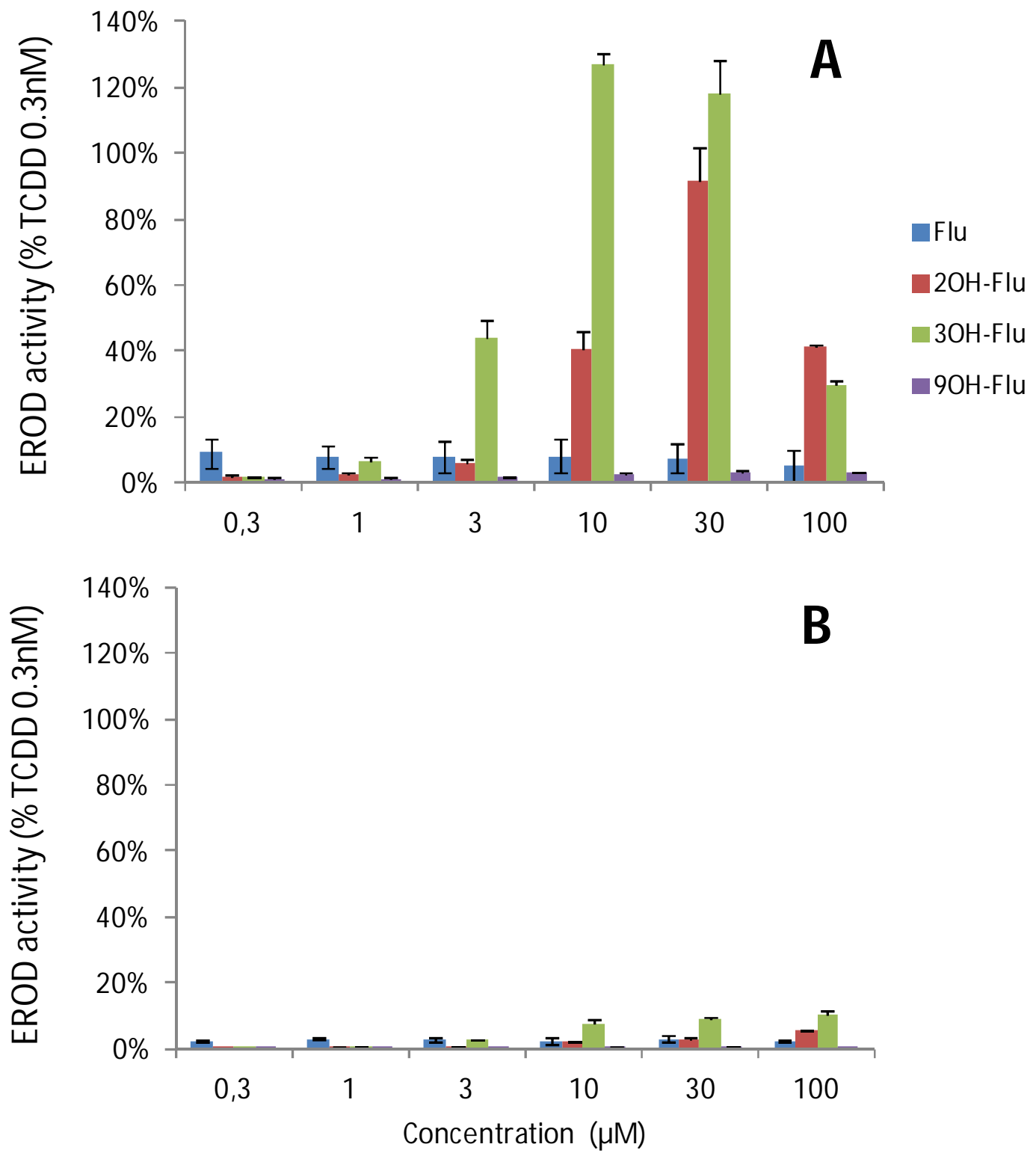

479 Table 1. Identified photoproducts resulting from UV-Vis irradiation of fluorene in water

\begin{tabular}{|c|c|c|c|c|c|c|}
\hline \multirow{2}{*}{ MW } & \multirow{2}{*}{$\begin{array}{c}\mathrm{Rt} \\
\text { (min.) }\end{array}$} & \multicolumn{3}{|c|}{ Main ions in mass spectra ${ }^{a}$} & \multicolumn{2}{|c|}{ Identified compounds } \\
\hline & & EI & $\mathrm{CI}$ & $\begin{array}{c}\mathrm{CI} \\
(\mathrm{DC})^{\mathrm{b}}\end{array}$ & Structure & Name \\
\hline
\end{tabular}




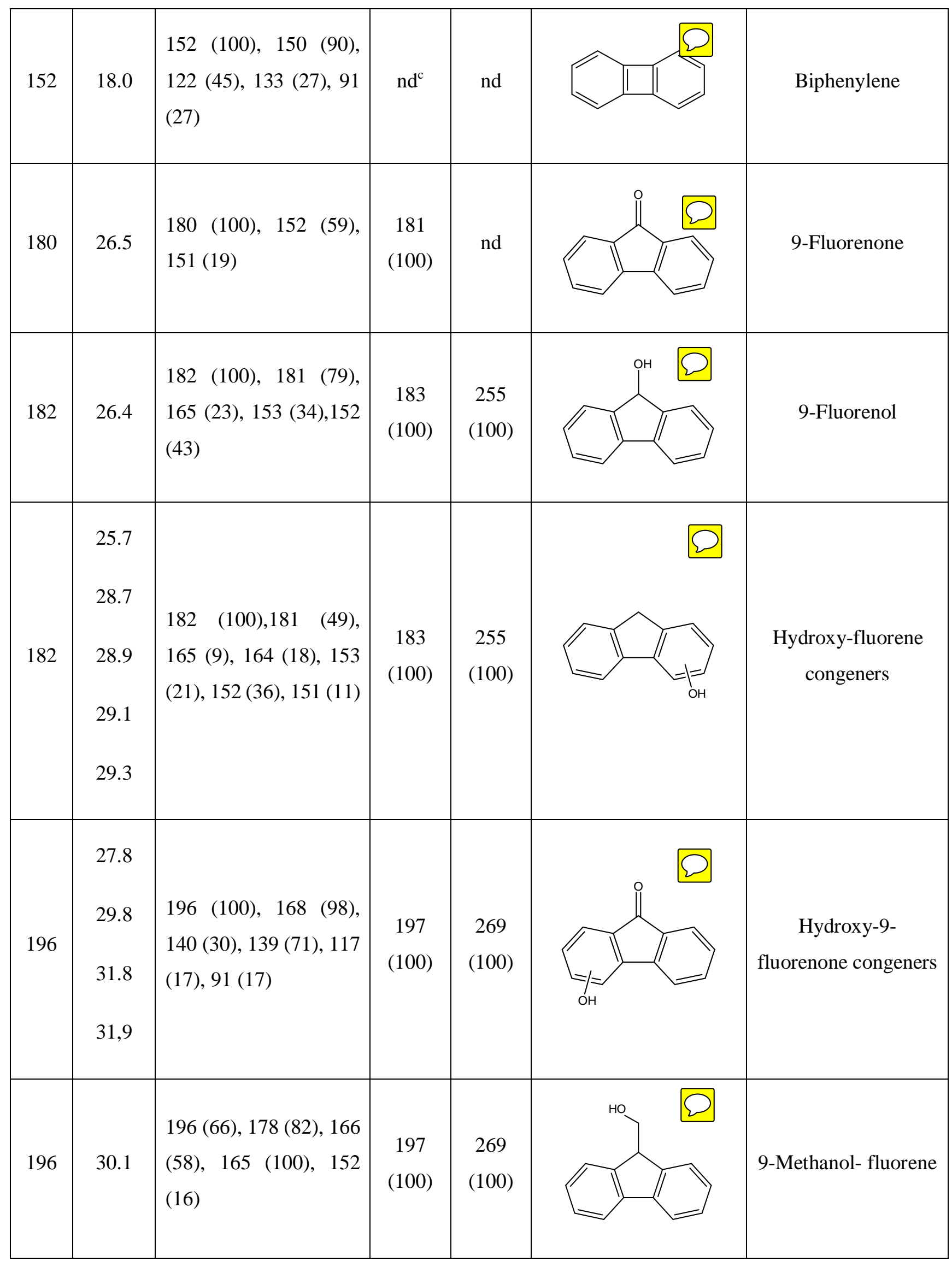




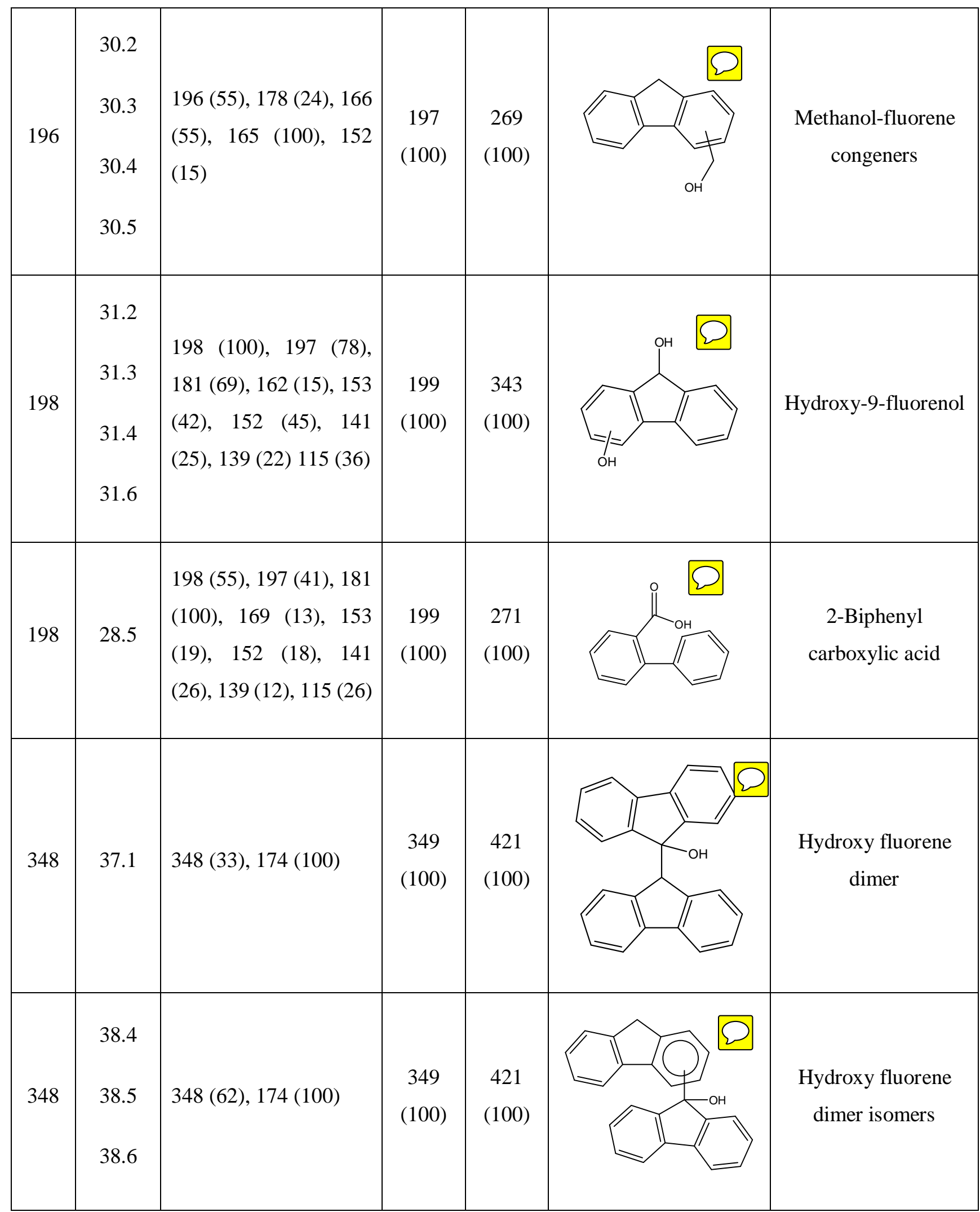

$480{ }^{\mathrm{a}}$ relative abundances $(\%)$ are given in parentheses $-{ }^{\mathrm{b}}$ DC: Derivatized compound $-{ }^{\mathrm{c}}$ nd: non 481 detected 
$\left.{ }^{1}\right]$ A. Orecchio, PAHs associated with the leaves of Quercus ilex L.: Extraction, GC-MS analysis, distribution and sources: Assessment of air quality in the Palermo (Italy) area, Atmos. Environ. 41 (2007) 8669-8680.

[2] R. Boonyatumanond, M. Murakami, G. Wattayakorn, A. Togo, H. Takada, Sources of polycyclic aromatic hydrocarbons (PAHs) in street dust in a tropical Asian mega-city, Bankok, Thailand, Sci. Total Environ. 384 (2007) 420-432.

$\left[{ }^{3}\right]$ S. Orecchio, Assessment of polycyclic aromatic hydrocarbons (PAHs) in soil of a Natural Reserve (Isola delle Femmine) (Italy) located in front of a plant for the production of cement, J. Hazard. Mater. 173 (2010) 358-368.

$\left[{ }^{4}\right]$ C.E. Bostrom, P. Gerde, A. Hanberg, B. Jernstrom, C. Johansson, T. Kyrklund, A. Rannug, M. Tornqvist, K. Victorin, R. Westerholm, Cancer risk assessment, indicators, and guidelines for polycyclic aromatic hydrocarbons in the ambient air, Environ. Health Persp. 110 (2002) 451-489.

[5] R. Kizu, K. Okamura, A. Toriba, H. Kakishima, A. Mizokami, K. Hayakawa, A role of aryl hydrocarbon receptor in the antiandrogenic effects of polycyclic aromatic hydrocarbons in LNCaP human prostate carcinoma cells, Arch. Toxicol. 77 (2003) 335-43.

[6] M.T. Wu, L.H. Lee, C.K. Ho, S.C. Wu, L.Y. Lin, B.H. Cheng, C.L. Lu, C.Y. Yang, H.T. Tsai, T.N. Wu, Environmental exposure to cooking oil fumes and cervical intraepithelial neoplasm, Environ. Res. 94 (2004) 25-32. 
$\left.{ }^{7}\right]$ M.D. Gammon, S.K. Sagiv, S.M., Eng, S. Shantakumar, M.M. Gaudet, S.L. Teitelbaum, J.A. Britton, M.B. Terry, L.W. Wang, Q. Wang, S.D. Stellman, J. Beyea, M. Hatch, G.C. Kabat, M.S Wolff, B. Levin, A.I. Neugut, R.M. Santella, Polycyclic aromatic hydrocarbon-DNA adducts and breast cancer: a pooled analysis, Arch. Environ. Health 59 (2004) 640-649.

$\left.{ }^{8}\right]$ J. Lewtas, Air pollution combustion emissions: Characterization of causative agents and mechanisms associated with cancer, reproductive, and cardiovascular effects, Muta. Res. 636 (2007) 95-133.

[9] ATSDR, 1995. Toxicological Profile for Polycyclic Aromatic Hydrocarbons, Atlanta: Agency for Toxic Substances and Disease Registry. Available at: www.atsdr.cdc.gov/toxprofiles.

$\left.{ }^{10}\right]$ W.G. Jeong, S.M. Cho, The effects of polycyclic aromatic hydrocarbon exposure on the fertilization and larval development of the Pacific oyster, Crassostrea gigas, J. Shellfish Res. 24 (2005) 209-213.

$\left[{ }^{11}\right]$ A. Ramesh, F. Inyang, D.D. Lunstrac, M.S. Niaz, P. Kopsombut, K.M. Jones, D.B. Hoode, E.R. Hills, A.E. Archibong, Alteration of fertility endpoints in adult male F-344 rats by subchronic exposure to inhaled benzo(a)pyrene, Exp. Toxicol. Pathol. 60 (2008) 269-280.

$\left.{ }^{[2}\right]$ Y. Han, Y., Xia, P. Zhu, S. Qiao, R. Zhao, N. Jin, S. Wang, L. Song, G. Fu, X. Wang, Reproductive hormones in relation to polycyclic aromatic hydrocarbon (PAH) metabolites among non-occupational exposure of males, Sci. Total Environ. 408 (2010) 768-773.

$\left[{ }^{13}\right]$ H.S. Lee, E.M. Cho, J.H. Jung, A. Ohta, Evaluation on antagonist activities of polycyclic aromatic hydrocarbons using the yeast two-hybrid detection system for endocrine disruptors, Environ. Monit. Assess. 129 (2007) 87-95. 
$\left.{ }^{14}\right]$ A.M. Vinggaard, J. Niemela, E.B. Wedebye, G.E. Jensen, Screening of 397 chemicals and development of a quantitative structure-activity relationship model for androgen receptor antagonism, Chem. Res. Toxicol. 21 (2008) 813-823.

$\left.{ }^{15}\right]$ I. Louiz, S. Kinani, M-E. Gouze, M. Ben-Atti, D. Menif, S. Bouchonnet, J.M. Porcher, O.K. Ben-Hassine, S. Aït-Aïssa, Monitoring of dioxin-like, estrogenic and anti-androgenic activities in sediments of the Bizerta lagoon (Tunisia) by means of in vitro cell-based bioassays: Contribution of low concentrations of polynuclear aromatic hydrocarbons (PAHs), Sci. Total Environ. 402 (2008) 318-329.

$\left.{ }^{16}\right]$ K. Ravindar, R. Sokhi, R., Van Grieken, Atmospheric polycyclic aromatic hydrocarbons: Source attribution, emission factors and regulation, Atmos. Environ. 42 (2008) 2895-2921.

$\left[{ }^{17}\right]$ E. Manoli, C. Samara, Polycyclic aromatic hydrocarbons in natural waters: sources, occurrence and analysis, Trends Anal. Chem. 18 (1999) 417- 428.

${ }^{18}{ }^{18}$ C.L. Gigliotti, P.A. Brunciak, J. Dachs, T.R. Glenn IV, E.D. Nelson, L.A. Totten, S.J. Eisenreich, Air-water exchange of polycyclic aromatic hydrocarbons in the New York-New Jersey Harbor estuary, USA, Environ. Toxicol. Chem. 21 (2002) 235-244.

$\left[{ }^{19}\right]$ M. Ángels Olivella, Polycyclic aromatic hydrocarbons in rainwater and surface waters of Lake Maggiore, a subalpine lake in Northern Italy, Chemosphere 63 (2006) 116-131.

$\left.{ }^{20}{ }^{2}\right]$ M.T. Pena, M.C. Casais, M.C. Mejuto, R. Cela, Development of an ionic liquid based dispersive liquid-liquid microextraction method for the analysis of polycyclic aromatic hydrocarbons in water samples, J. Chrom. A 1216 (2009) 6356-6364.

$\left.{ }^{21}\right]$ R. Götz, O.H. Auer, P. Friesel, K. Roch, Organic trace compounds in the water of the River Elbe near Hamburg, Chemosphere 36 (1998) 2103-2118. 
$\left.{ }^{22}\right]$ A. Ballesteros-Gómez, S. Rubio, D. Pérez-Bento, Determination of priority carcinogenic polycyclic aromatic hydrocarbons in wastewater and surface water by coacervative extraction and liquid chromatography-fluorimetry, J. Chrom. A 1203 (2008) 168-176.

$\left[{ }^{23}\right]$ E. Pérez-Cerrera, V.M. León A.G. Parra, E. González-Mazo, Simultaneous determination of pesticides, polycyclic aromatic hydrocarbons and polychlorinated biphenyls in seawater and interstitial marine water samples, using stir bar sorptive extraction-thermal desorption-gas chromatography-mass spectrometry, J. Chrom. A 1170 (2007) 82-90.

$\left.{ }^{[24}\right]$ A. Valavanidis, T. Vlachogianni, S. Triantafillaki, M. Dassenakis, F. Androutsos, M. Scoullos, Polycyclic aromatic hydrocarbons in surface seawater and in indigenous mussels (Mytilus galloprovincialis) from coastal areas of the Saronikos Gulf (Greece), Estuar. Coast. Shelf S. 79 (2008) 733-739.

$\left[{ }^{25}\right]$ S. Bertilsson, A. Widenfalk, Photochemical degradation of PAHs in freshwaters and their impact on bacterial growth - influence of water chemistry, Hydrobiologia 469 (2002) 23-32.

$\left.{ }^{26}\right]$ C.D. Clark, W.J. De Bruyn, J. Ting, W. Scholle, Solution medium effects on the photochemical degradation of pyrene in water, J. Photoch. Photobio. A 186 (2007) 342-348.

$\left[{ }^{27}\right]$ O.T. Woo, W.K. Chung, K.H. Wong, A.T. Chow, P.K. Wong, Photocatalytic oxidation of polycyclic aromatic hydrocarbons: intermediates identification and toxicity testing, J. Hazard. Mater. 168 (2009) 1192-1199.

$\left[{ }^{28}\right]$ R. Dabestani, L.N. Ivanov, Invited Review: A compilation of physical, spectroscopic and photophysical properties of polycyclic aromatic hydrocarbons, Photochem. Photobiol. 70 (1999) 103-134. 
$\left[{ }^{29}\right]$ L. Rizzo, Bioassays as a tool for evaluating advanced oxidation processes in water and wastewater treatment, Water Res. 45 (2011) 4311-4340.

$\left[{ }^{30}\right]$ W.R. Gala, J.P. Giesy, Flow cytometric determination of the photo induced toxicity of anthracene to the green alga Selenastrum capricornutum, Environ. Toxicol. Chem. 13 (1994) 831-840.

$\left[{ }^{31}\right]$ H. Shemer, K.G. Linden, Aqueous photodegradation and toxicity of the polycyclic aromatic hydrocarbons fluorene, dibenzofuran and dibenzothiophene, Water Res. 41 (2007) 853-861.

$\left[{ }^{32}\right]$ S. Kinani, S. Bouchonnet, N. Creusot, S. Bourcier, P. Balaguer, J.M. Porcher, S. Aït-Aïssa, Bioanalytical characterisation of multiple endocrine- and dioxin-like activities in sediments from reference and impacted small rivers, Environ. Pollut. 158 (2010) 74-83.

$\left[{ }^{33}\right]$ S. Kinani, S. Bouchonnet, S. Bourcier, N. Creusot, J.M. Porcher, S. Aït-Aïssa, Extraction and purification procedures for simultaneous quantification of phenolic xenoestrogens and steroid estrogens in river sediment by gas chromatography/ion trap mass spectrometry, Rapid Comm. Mass Spectrom. 22 (2008) 3651-3661.

$\left[{ }^{34}\right]$ P. Balaguer, A.M. Boussioux, E. Demirpence, J.C. Nicolas, Reporter cell lines are useful tools for monitoring biological activity of nuclear receptor ligands, Luminescence 16 (2001) $153-158$.

$\left[{ }^{35}\right]$ T. Mossman, Rapid colorimetric assay for cellular growth and survival: application to proliferation and cytotoxicity assays, J. Immunol. 65 (1983) 55-63.

$\left.{ }^{36}\right]$ N. Laville, S. Aït-Aïssa, E. Gomez, C. Casellas, J.M. Porcher, Effects of human pharmaceuticals on cytotoxicity, EROD activity and ROS production in fish hepatocytes, Toxicology 2004, 196, 41-55. 
$\left[{ }^{37}\right]$ F.J. Rivas, F.J. Beltran, O. Gimeno, M. Carbajo, Fluorene oxidation by coupling of ozone, radiation, and semiconductors: A mathematical approach to the kinetics, Ind. Eng. Chem. Res. 45 (2006) 166-174.

$\left[{ }^{38}\right]$ NIST Standard Reference Data. 2012. http://www.nist.gov/srd/nist1a.cfm.

$\left[{ }^{39}\right]$ L. Hykrdova, J. Jirkovsky, G. Mailhot, M. Bolte, Fe(III) photoinduced and Q-TiO2 photocatalysed degradation of naphthalene: comparison of kinetics and proposal of mechanism, J. Photoch. Photobio. A 151 (2002) 181-193.

$\left.{ }^{40}\right]$ M.J. García-Martínez, L. Canoira, G. Blázquez, I. Da Riva, R. Alcántara, J.F. Llamas, Continuous photodegradation of naphthalene in water catalyzed by $\mathrm{TiO} 2$ supported on glass Raschig rings, Chem. Eng. J. 110 (2005) 123-128.

$\left[{ }^{41}\right]$ T. Ohno, T. Mitsui, M. Matsumura, Photocatalytic activity of S-doped $\mathrm{TiO}_{2}$ photocatalyst under visible light, Chem. Lett. 32 (2003) 364-365.

$\left[{ }^{42}\right]$ M. Muneer, M. Qamar, M. Saquib, D. Bahnemann, Heterogeneous photocatalysed reaction of three selected pesticide derivatives, propham, propachlor and tebuthiuron in aqueous suspension of titanium dioxide, Chemosphere 61 (2005) 457-468.

$\left[{ }^{43}\right]$ A. Lair, C. Ferronato, J.M. Chovelon, J.M. Herrmann, Naphthalene degradation in water by heterogeneous photocatalysis: An investigation of the influence of inorganic anions, J. Photoch. Photobio. A 193 (2008) 193-203.

$\left[{ }^{44}\right]$ J.S. Miller, D. Olejnik, Photolysis of polycyclic aromatic hydrocarbons in water, Water Res. 35 (2001) 233-243. 
$\left[{ }^{45}\right]$ D. Dabrowska, A. Kot-Wasik, J. Namiesnik, Stability studies of selected polycyclic aromatic hydrocarbons in different organic solvents and identification of their transformation products, Pol. J. Environ. Stud. 17 (2008) 17-24.

$\left.{ }^{[46}\right]$ J. Sabaté, J.M. Bayona, A.M. Solanas, Photolysis of PAHs in aqueous phase by UV irradiation, Chemosphere 44 (2001) 119-124.

$\left[{ }^{47}\right]$ M. Kamiya, A. Toriba, Y. Onoda, R. Kizu, K. Hayakawa, Evaluation of estrogenic activities of hydroxylated polycyclic aromatic hydrocarbons in cigarette smoke condensate, Food Chem. Toxicol. 43 (2005) 1017-1027.

$\left[{ }^{48}\right]$ T.W. Schultz, G.D. Sinks, Xenoestrogenic gene exression: Structural features of active polycyclic aromatic hydrocarbons, Environ. Toxicol. Chem. 21 (2002) 783-786.

$\left[{ }^{49}\right]$ N.C. Bols, K. Schirmer, E.M. Joyce, D.G. Dixon, B.M. Greenberg, J.J. Whyte, Ability of polycyclic aromatic hydrocarbons to induce 7-ethoxyresorufin-O-deethylase activity in a trout liver cell line, Ecotoxicol. Environ. Safety 44 (1999) 118-128.

$\left[{ }^{50}\right]$ W. Brack, Effect-directed analysis: a promising tool for the identification of organic toxicants in complex mixtures? Anal. Bioanal. Chem. 377 (2003) 397-407.

$\left[{ }^{51}\right]$ N. Creusot, H. Budzinski, P. Balaguer, S. Kinani, J.M. Porcher, S. Aït-Aïssa, Effect directed analysis of endocrine disrupting compounds in multi-contaminated sediment: identification of novel ligands of estrogen and pregnane X receptors, Anal. Bioanal. Chem. 405 (2013) 25532566.

$\left[{ }^{52}\right]$ T. Schulze, S. Weiss, E. Schymanski, P.C. von der Ohe, M. Schmitt-Jansen, R. Altenburger, G. Streck, W. Brack, Identification of a phytotoxic photo-transformation product of diclofenac using effect-directed analysis, Environ. Pollut. 158(5) (2010) 1461-1466. 
$\left[{ }^{53}\right]$ Y. Souissi, S. Kinani, S. Bouchonnet, S. Bourcier, C. Malosse, M. Sablier, N. Creusot, E. Mombelli, S. Aït-Aïssa, Photolysis of estrone generates estrogenic photoproducts with higher activity than the parent compound, Environ. Sci. Pollut. R. 21 (2014) 7818-7827. 